\title{
Teores de ácidos graxos trans de alguns alimentos consumidos no Rio de Janeiro ${ }^{1}$
}

\section{Trans fatty acids of some foods consumed in Rio de Janeiro, Brazil}

Vera Lúcia CHIARA2

Rosely SICHIERI ${ }^{3}$

Tatiana dos Santos Ferreira de CARVALHO ${ }^{4}$

\section{RE S U M O}

Desconhecem-se os teores de ácidos graxos trans em diversos alimentos. Este estudo analisou os teores de ácidos graxos trans, saturados, monoinsaturados e poliinsaturados em batatas fritas, biscoitos e sorvetes. As batatas fritas foram dos tipos chips e de duas redes de fast food, os sorvetes, de duas marcas comerciais e de duas lojas de fast food, e os biscoitos, de marcas diferentes. As amostras de batatas chips e de biscoitos pertenciam a lotes distintos e foram adquiridas em supermercados da região. Analisaram-se seis amostras por produto, através de cromatografia gasosa. 0 valor médio dos ácidos trans de batatas fritas de redes de fast food foi de $4,74 \mathrm{~g} / 100 \mathrm{~g}$, enquanto em batatas chips estes ácidos graxos não foram detectados. Nos sorvetes os valores variaram de 0,041g a 1,41g e em biscoitos, de $2,81 \mathrm{~g}$ a $5,60 \mathrm{~g}$. Biscoitos tipo cream cracker apresentaram teores de ácidos graxos trans mais altos e de insaturados mais baixos. Concluiu-se que alguns produtos apresentaram, em $100 \mathrm{~g}$, teores de ácidos graxos trans superiores aos recomendados para ingestão total diária em diversos países.

Termos de indexação: ácidos graxos trans, alimentos, isômeros trans.

\footnotetext{
1 Elaborado a partir da tese de doutorado em Epidemologia de V.L.P. CHIARA, "Avaliação N utricional de Adolescentes como Instrumento na Prevenção de Doenças Cardiovasculares". Programa de Pós-Graduação em Saúde Coletiva - Área de Concentração de Epidemiologia, do Instituto de Medicina Social, Universidade Estadual do Rio de Janeiro.

2 Departamento de N utrição Social, Instituto de N utrição, Universidade Estadual do Rio de Janeiro. Rua São Francisco Xavier, n. 524, 12 andar, sala 12001, Maracanã, 20559-900, Rio de Janeiro, RJ, Brasil. Correspondência para/Correspondence to: V.L. CHIARA. E-mail: chiara@uerj.br ou vchiara@easynet.com.br

${ }^{3}$ Departamento de Epidemiologia, Instituto de Medicina Social, Universidade Estadual do Rio de Janeiro.

${ }^{4}$ Bolsista de Estágio Complementar, Instituto de Nutrição, Universidade Estadual do Rio de Janeiro.
} 


\section{A B S T R A C T}

The content of trans fatty acids in most consumed foods in Brazil is unknown. This study assessed trans saturated, monounsaturated and polyunsaturated fatty acids in samples of fried potatoes, cookies and ice cream. The analysis included: potato chips and fried potatoes from two popular fast food restaurants, ice cream of two different trademarks and from two fast food restaurants, and cookies of different trademarks. The samples of potato chips and cookies were acquired in different supermarkets in the city of Rio de Janeiro, and distinct manufacture dates were chosen. Six samples of each product were analyzed through gas chromatography. The average trans fatty acids content in fried potatoes from fast food restaurants was $4.74 \mathrm{~g} /$ $100 \mathrm{~g}$; in ice cream the values varied from $0.041 \mathrm{~g}$ to $1.41 \mathrm{~g}$; and in cookies the values varied from $2.81 \mathrm{~g}$ to $5.60 \mathrm{~g}$. No trans fatty acids were found in potato chips. Cream crackers had the highest values of trans fatty acids and the low est content of unsaturated fat. In some products, the content of trans fatty acids in $100 \mathrm{~g}$ was higher than the daily total intake recommended in several countries.

Index terms: trans fatty acids, food, trans isomers.

\section{N T R O D U Ç Ã O}

Os ácidos graxos trans foram, recentemente, incluídos entre os lipídios dietéticos que atuam como fatores de risco para doença arterial coronariana, modulando a síntese do colesterol e suas frações e atuando sobre os eicosanóides ${ }^{1,2}$.

Esses ácidos estão presentes naturalmente em gorduras originadas de animais ruminantes, como resultado do processo de biohidrogenação de alguns tipos de rações na flora microbiana do rumen ${ }^{3}$, e em produtos alimentícios industrializados que sofrem processo de hidrogenação parcial ou total de óleos vegetais ou marinhos ${ }^{4}$. Em produtos alimentícios manufaturados, são encontrados em margarinas duras e algumas cremosas, creme vegetal, gordura vegetal hidrogenada, biscoitos, sorvetes, alguns pães, batatas fritas (fast food), pastelarias, bolos, massas, entre outros.

Nas últimas décadas, o consumo de margarina vem se elevando no Brasil, através da substituição da manteiga ${ }^{5}$ e do crescente aumento na manufatura e na ingestão de produtos alimentícios industrializados contendo gordura hidrogenada ${ }^{6}$. Além disso, as gorduras hidrogenadas e as margarinas nacionais apresentam teores mais elevados de ácidos graxos trans, em comparação com similares estrangeiros ${ }^{7}$.

Embora desde 1995 a Organização Mundial da Saúde venha recomendando a ingestão moderada deste tipo de gordura na prevenção e tratamento de doenças coronarianas, até o presente são desconhecidos os teores de ácidos graxos trans nos alimentos industrializados, prejudicando a orientação em relação ao seu consumo. No Brasil, uma portaria do Ministério da Saúde, datada de 17 de outubro de 1997, estabelece que a quantidade desses ácidos nos produtos deve estar computada como ácidos graxos saturados, permanecendo desconhecidos os teores específicos de ácidos graxos trans ${ }^{8}$. Assim, a questão da inclusão de informações mais completas em rótulos de produtos vem sendo retomada e discutida por órgãos governamentais no país. Em 1999, a Food and Drug Administration (FDA) sugeriu que a quantidade de ácidos graxos trans fosse incluída em rótulos de produtos, recomendando, quando computada em gorduras saturadas, a demarcação por símbolo informativo da quantidade específica de ácidos graxos trans ${ }^{9}$.

Neste trabalho, objetivando fornecer subsídios para outros estudos nesta área, foram estabelecidos os teores de ácidos graxos trans em três tipos de alimentos freqüentemente consumidos por adolescentes do município do Rio de Janeiro ${ }^{10}$.

\section{MATERIALE MÉTODOS}

Foram analisados três produtos: batatas fritas, sorvetes e biscoitos. Foram adquiridos três 
tipos de batatas fritas e de biscoitos, e quatro tipos de sorvetes. Para cada tipo de produto foram obtidas 6 amostras, totalizando 18 amostras de batatas fritas, 24 de sorvetes e 18 de biscoitos.

As batatas fritas foram agrupadas em produto industrializado (chips) e produtos provenientes de duas redes de alimentos (fast food) definidos como amostras tipos 1 e 2. As batatas fritas chips foram adquiridas em seis supermercados do Rio de Janeiro e eram da mesma marca comercial com diferentes datas de produção. As amostras 1 e 2 foram compradas em 12 lojas distintas distribuídas por toda a região do município do Rio de Janeiro.

Os sorvetes foram de quatro tipos definidos como A, B, C e D, agrupados da seguinte forma: no tipo $A$, sorvetes de dois sabores (crocante $e$ creme), de marca comum na região; no tipo $B$, sorvetes de três sabores (chocolate, morango e creme), de outra marca comercial; e nos tipos C e $D$, sundae com cobertura de chocolate ou morango, das mesmas lojas de fast food anteriormente citadas.

As amostras de biscoitos foram numeradas como: 1 para os biscoitos cream cracker, 2 para os recheados de sabor chocolate e 3 para os de sabor morango. Os tipos de biscoitos pertenciam a marcas distintas, porém as amostras para cada tipo foram da mesma marca comercial. Essas amostras foram adquiridas em diferentes supermercados da região e pertenciam a lotes distintos.

As análises estiveram a cargo de instituição contratada, a Empresa Brasileira de Pesquisa Agropecuária (EMBRAPA), e foram realizadas através de cromatografia gasosa, de acordo com o estabelecido no método oficial da Association of Official Analytical Chemists (AOAC 994.06) ${ }^{11}$. As amostras foram submetidas à digestão ácida $e$ os lipídios foram extraídos com éter etílico e de petróleo; este processo foi seguido de metilação para produção de ésteres metílicos, que foram analisados por cromatografia gasosa em cromatógrafo HP 5890, em coluna capilar de sílica fundida de SP 2340, com temperatura variando de $150^{\circ} \mathrm{C}$ a $200^{\circ} \mathrm{C}$, com taxa de $1,3^{\circ} \mathrm{C} /$ minuto e fluxo de hidrogênio de $2,45 \mathrm{~mL} /$ minuto, em duplicata.

Definiram-se os teores totais de: ácidos graxos trans, diferentes tipos de isômeros trans, lipídios saturados, monoinsaturados e poliinsaturados. Esses valores foram apresentados por 100 gramas de cada tipo de produto analisado.

\section{RES U LT A D O S}

Em batatas fritas do tipo chips os teores de ácid os graxos saturados foram três vezes mais elevados do que no tipo 1 e duas vezes mais do que no tipo 2, sendo estes últimos tipos, originários de lojas de fast food. Totalizando-se os teores de ácidos graxos insaturados (monoinsaturados e poliinsaturados) presentes na batata chips, encontrou-se o triplo do observado nas demais variedades (Tabelas 1 e 2 ).

Entre os sorvetes, os teores de ácidos graxos saturados e monoinsaturados foram similares, enquanto os poliinsaturados predominaram no tipo $B$, referente aos sorvetes de três sabores.

Em relação às batatas fritas, elevados teores de ácidos graxos trans foram encontrados naquelas provenientes de lojas de fast food, estando ausentes em batatas chips. 0 inverso ocorreu com os sorvetes: os teores de ácidos graxos trans foram mais reduzidos naqueles originados de lojas de fast food (Tabela 3).

O ácido graxo elaídico (C18:1 trans), isômero do ácido graxo oléico, foi predominante em batatas fritas adquiridas nas lojas de fast food, em sorvetes dos tipos A e B de marcas comerciais comuns na região e em todos os tipos de biscoitos.

As amostras de biscoitos do tipo cream cracker apresentaram os mais elevados teores de ácidos graxos trans totais. Em biscoitos não se observou a presença de ácidos graxos saturados de cadeia curta, característico de gordura láctea (manteiga), enquanto o ácido graxo monoinsaturado oléico surgiu em todas as análises. As amostras de biscoitos recheados apresentaram valores mais elevados de ácido graxo poliinsaturado (linoléico). 
Tabela 1. Ácidos graxos saturados em gramas por 100 gramas do alimento segundo tipos.

\begin{tabular}{|c|c|c|c|c|c|c|c|c|c|c|}
\hline \multirow{2}{*}{ Ácidos Graxos (g) } & \multicolumn{3}{|c|}{ Batatas Fritas \pm DP } & \multicolumn{4}{|c|}{ Sorvetes $\pm \mathrm{DP}$} & \multicolumn{3}{|c|}{ Biscoitos $\pm \mathrm{DP}$} \\
\hline & Chips & 1 & 2 & $A$ & B & C & D & 1 & 2 & 3 \\
\hline Capróico & - & - & - & - & - & $0,01 \pm$ & $0,013 \pm$ & - & - & - \\
\hline C6:0 & & & & & & 0,006 & 0,030 & & & \\
\hline Caprílico & - & - & - & traços & $0,05 \pm$ & $0,01 \pm$ & $0,014 \pm$ & - & - & - \\
\hline C 8:0 & & & & & 0,000 & 0,022 & 0,003 & & & \\
\hline Cáprico & - & - & - & $0,02 \pm$ & traços & $0,04 \pm$ & $0,028 \pm$ & - & - & - \\
\hline $\mathrm{C} 10: 0$ & & & & 0,007 & & 0,007 & 0,005 & & & \\
\hline Láurico & $0,13 \pm$ & - & - & $0,02 \pm$ & $0,02 \pm$ & $0,04 \pm$ & $0,04 \pm$ & - & traços & traços \\
\hline C12:0 & 0,006 & & & 0,001 & 0,015 & 0,008 & 0,007 & & & \\
\hline M irístico & $0,32 \pm$ & $0,07 \pm$ & $0,08 \pm$ & $0,07 \pm$ & $0,05 \pm$ & $0,16 \pm$ & $0,132 \pm$ & traços & $0,05 \pm$ & $0,03 \pm$ \\
\hline $\mathrm{C} 14: 0$ & 0,029 & 0,004 & 0,007 & 0,001 & 0,005 & 0,033 & 0,003 & & 0,033 & 0,006 \\
\hline Pentadecílico & Traços & - & - & traços & traços & $0,02 \pm$ & $0,025 \pm$ & - & - & - \\
\hline C15:0 & & & & & & 0,004 & 0,003 & & & \\
\hline Palmítico & $14,46 \pm$ & $2,71 \pm$ & $4,34 \pm$ & $0,69 \pm$ & $0,54 \pm$ & $0,71 \pm$ & $0,455 \pm$ & $2,08 \pm$ & $2,56 \pm$ & $2,50 \pm$ \\
\hline C16:0 & 0,936 & 0,274 & 0,514 & 0,014 & 0,018 & 0,124 & 0,011 & 0,361 & 0,070 & 0,173 \\
\hline Esteárico & $1,73 \pm$ & $1,79 \pm$ & $2,09 \pm$ & $0,60 \pm$ & $0,52 \pm$ & $0,38 \pm$ & $0,294 \pm$ & $1,76 \pm$ & $1,76 \pm$ & $1,76 \pm$ \\
\hline C18:0 & 0,105 & 0,264 & 0,209 & 0,133 & 0,003 & 0,050 & 0,006 & 0,422 & 0,013 & 0,076 \\
\hline Araquídico & $0,16 \pm$ & traços & traços & traços & traços & $0,01 \pm$ & $0,01 \pm$ & traços & traços & - \\
\hline$C 20: 0$ & 0,020 & & & & & 0,007 & 0,000 & & & \\
\hline Beênico & traços & traços & traços & - & traços & traços & - & traços & $0,08 \pm$ & $0,08 \pm$ \\
\hline C22:0 & & & & & & & & & 0,000 & 0,000 \\
\hline Total & 16,800 & 4,570 & 6,510 & 1,400 & 1,180 & 1,380 & 1,024 & 3,840 & 4,450 & 4,370 \\
\hline
\end{tabular}

Tabela 2. Ácidos graxos insaturados em gramas por 100 gramas do alimento segundo tipos.

\begin{tabular}{|c|c|c|c|c|c|c|c|c|c|c|}
\hline \multirow{2}{*}{ Ácidos Graxos (g) } & \multicolumn{3}{|c|}{ Batatas Fritas $\pm \mathrm{DP}$} & \multicolumn{4}{|c|}{ Sorvetes $\pm \mathrm{DP}$} & \multicolumn{3}{|c|}{ Biscoitos \pm DP } \\
\hline & Chips & 1 & 2 & A & B & C & D & 1 & 2 & 3 \\
\hline \multicolumn{11}{|l|}{ Monoinsaturados } \\
\hline $\begin{array}{l}\text { M iristoléico } \\
\text { C14:1 }\end{array}$ & - & - & - & traços & traços & $\begin{array}{l}0,03 \pm \\
0,006\end{array}$ & $\begin{array}{l}0,026 \pm \\
0,004\end{array}$ & - & - & - \\
\hline $\begin{array}{l}\text { Palmitoléico } \\
\text { C16:1 }\end{array}$ & traços & traços & traços & traços & traços & 0,02 & $\begin{array}{l}0,026 \pm \\
0,004\end{array}$ & traços & traços & traços \\
\hline $\begin{array}{l}\text { Oléico } \\
\text { C18:1 }\end{array}$ & $\begin{array}{l}14,76 \pm \\
0,942\end{array}$ & $\begin{array}{l}3,67 \pm \\
0,582\end{array}$ & $\begin{array}{l}5,69 \pm \\
0,764\end{array}$ & $\begin{array}{l}1,19 \pm \\
0,045\end{array}$ & $\begin{array}{l}1,22 \pm \\
0,071\end{array}$ & $\begin{array}{l}0,63 \pm \\
0,085\end{array}$ & $\begin{array}{l}0,488 \pm \\
0,013\end{array}$ & $\begin{array}{l}3,43 \pm \\
0,748\end{array}$ & $\begin{array}{l}4,31 \pm \\
0,057\end{array}$ & $\begin{array}{l}4,44 \pm \\
0,366\end{array}$ \\
\hline $\begin{array}{l}\text { Eicosanóico } \\
\text { C20:1 }\end{array}$ & - & traços & traços & - & - & $\begin{array}{l}0,03 \pm \\
0,018\end{array}$ & $\begin{array}{l}0,02 \pm \\
0,000\end{array}$ & traços & - & traços \\
\hline Total & 14,76 & 3,67 & 5,69 & 1,19 & 1,22 & 0,71 & 0,56 & 3,43 & 4,31 & 4,44 \\
\hline \multicolumn{11}{|l|}{ Poliinsaturados } \\
\hline $\begin{array}{l}\text { Linoléico } \\
\text { C18:2 }\end{array}$ & $\begin{array}{l}3,37 \pm \\
0,241\end{array}$ & $\begin{array}{l}1,73 \pm \\
0,220\end{array}$ & $\begin{array}{l}1,10 \pm \\
0,162\end{array}$ & $\begin{array}{l}0,25 \pm \\
0,003\end{array}$ & $\begin{array}{l}0,10 \pm \\
0,034\end{array}$ & $\begin{array}{l}0,07 \pm \\
0,012\end{array}$ & $\begin{array}{l}0,046 \pm \\
0,004\end{array}$ & $\begin{array}{l}0,90 \pm \\
0,111\end{array}$ & $\begin{array}{l}2,86 \pm \\
0,178\end{array}$ & $\begin{array}{l}3,34 \pm \\
0,652\end{array}$ \\
\hline $\begin{array}{l}\alpha \text {-linoléico } \\
\text { C18:3 }\end{array}$ & $\begin{array}{l}0,12 \pm \\
0,002\end{array}$ & traços & traços & traços & - & traços & traços & traços & $\begin{array}{l}0,12 \pm \\
0,027\end{array}$ & $\begin{array}{l}0,17 \pm \\
0,050\end{array}$ \\
\hline Total & 3,490 & 1,730 & 1,100 & 0,250 & 0,100 & 0,070 & 0,046 & 0,900 & 2,980 & 3,510 \\
\hline
\end{tabular}


Tabela 3. Teores em gramas de ácidos graxos trans por 100 gramas de alimentos nas amostras segundo tipos de produtos.

\begin{tabular}{|c|c|c|c|c|c|c|c|c|c|c|}
\hline \multirow{2}{*}{ Ácidos Graxos (g) } & \multicolumn{3}{|c|}{ Batatas Fritas \pm DP } & \multicolumn{4}{|c|}{ Sorvetes \pm DP } & \multicolumn{3}{|c|}{ Biscoitos \pm DP } \\
\hline & Chips & 1 & 2 & A & B & C & D & 1 & 2 & 3 \\
\hline C18:1 trans & traços & $\begin{array}{l}4,32 \pm \\
0,670\end{array}$ & $\begin{array}{l}4,73 \pm \\
0,450\end{array}$ & $\begin{array}{r}1,08 \pm \\
0,039\end{array}$ & $\begin{array}{l}1,14 \pm \\
0,157\end{array}$ & $\begin{array}{l}0,14 \pm \\
0,021\end{array}$ & $\begin{array}{l}0,041 \\
\pm 0,007\end{array}$ & $\begin{array}{l}5,38 \pm \\
1,273\end{array}$ & $\begin{array}{l}2,16 \pm \\
0,600\end{array}$ & $\begin{array}{l}2,11 \pm \\
0,083\end{array}$ \\
\hline C18:2 trans-trans & traços & traços & traços & $\begin{array}{l}0,05 \pm \\
0,007\end{array}$ & $\begin{array}{l}0,07 \pm \\
0,048\end{array}$ & - & - & $\begin{array}{l}0,22 \pm \\
0,057\end{array}$ & $\begin{array}{l}0,19 \pm \\
0,002\end{array}$ & $\begin{array}{l}0,19 \pm \\
0,010\end{array}$ \\
\hline $\begin{array}{l}\text { C18:2 isômero- } \\
\text {-trans }\end{array}$ & - & $\begin{array}{l}0,44 \pm \\
0,144\end{array}$ & traços & traços & $\begin{array}{l}0,19 \pm \\
0,132\end{array}$ & - & - & traços & $\begin{array}{l}0,46 \pm \\
0,046\end{array}$ & $\begin{array}{l}0,56 \pm \\
0,087\end{array}$ \\
\hline Total & - & 4,760 & 4,730 & 1,130 & 1,400 & 0,140 & 0,041 & 5,600 & 2,810 & 2,860 \\
\hline
\end{tabular}

\section{I S C U S S Ã O}

As batatas fritas chips demonstraram apenas traços de ácidos graxos trans na composição, eliminando a inclusão de gordura hidrogenada no preparo. Supõe-se que estes traços sejam originários dos próprios óleos vegetais utilizados na preparação, pois traços de isômeros trans podem ser formados durante reações químicas, como a oxidação que ocorre na extração, refinação e armazenamento dos óleos vegetais ${ }^{12}$. A composição lipídica destas amostras de batatas fritas parece distinta daquela de similares americanos. Em 20 amostras de batatas fritas desse tipo analisadas nos EUA encontraram-se 10,88 gramas de ácidos graxos trans, sendo predominante a presença do ácido graxo elaídico, comum em gordura hidrogenada. Este tipo de ácido graxo trans, na presente pesquisa, foi encontrado somente em amostras de batatas fritas originadas de lojas de fast food. Estes produtos, embora tenham sido adquiridos em lojas de fast food de duas redes distintas, parecem sofrer preparo semelhante ao observado na análise de 11 amostras de batatas fritas americanas do mesmo tipo, uma vez que também revelaram elevados teores de ácido graxo elaídico, isômero do ácido graxo insaturado oléico ${ }^{13}$. Ressalta-se que, em estudo analisando a composição lipídica de diversas amostras de batatas fritas comercializadas no Rio de Janeiro, observou-se a utilização de óleos vegetais de soja e canola, parcialmente hidrogenados, os quais apresentam em sua composição o ácido graxo oléico ${ }^{14}$.
A presença de reduzidos teores de ácidos graxos de cadeia curta indica ausência de gordura láctea nas amostras de sorvetes, enquanto os teores dos ácidos graxos C18:1cis (oléico) e C18:1trans (elaídico) apontam para uso reduzido de gordura hidrogenada no preparo dos sorvetes dos tipos A e B. As amostras desses tipos de sorvetes utilizadas neste estudo relataram, nos rótulos, a presença tanto de gordura láctea quanto de gordura hidrogenada. Em sorvetes, os mais baixos teores de lipídios trans foram encontrados nos tipos $C$ e $D$, os quais não apresentam informações na embalagem, uma vez que são produzidos e servidos no momento da aquisição em lojas de fast food.

Os resultados encontrados neste trabalho para os sorvetes diferem do obtido em análise de dez amostras de sorvetes do mercado paulista em $1993^{15}$. Na referida pesquisa, observaram-se em três amostras o uso exclusivo de gordura láctea e em apenas uma delas, a presença exclusiva de gordura hidrogenada, enquanto as seis amostras restantes indicaram a utilização de ambos os tipos de gorduras.

A diferença entre os ácidos graxos trans provenientes de gordura láctea e os de gordura hidrogenada não se refere apenas às quantidades, reduzidas na primeira e elevadas na segunda, mas também está relacionada ao tipo de isômero predominante em um e em outro. Entre os ácidos graxos trans resultantes do processo de biohidrogenação, há o predomínio do ácido vacênico, enquanto na gordura que sofre 
hidrogenação prevalece o ácido elaídico. Considera-se o ácido elaídico o principal competidor do linoléico no metabolismo humano, principalmente quando a ingestão deste é reduzida ${ }^{16}$. Sugere-se que dietas ricas em competidores e moderadores de ácidos graxos essenciais podem gerar mudanças na produção e formação de prostaglandinas e tromboxanos (eicosanóides), os quais têm como precursores os ácidos graxos poliinsaturados linoléico e $\alpha$-linolênico ${ }^{17}$. Além disso, a ação competitiva dos ácidos graxos trans com os poliinsaturados pode refletir-se sobre a redução do número de receptores de lipoproteínas de baixa densidade (LDL-C), contribuindo para a elevação de seus níveis plasmáticos ${ }^{13}$.

Todas as amostras de biscoito apresentaram em seus rótulos a inclusão de gordura vegetal hidrogenada, informação confirmada através da identificação, nas análises, do ácido graxo elaídico. As amostras de biscoitos do tipo cream cracker obtiveram os teores mais elevados de ácidos graxos trans. 0 consumo de 100 gramas desse tipo de biscoito extrapola a recomendação de $2 \%$ a $5 \%$ de ácidos graxos trans em relação ao valor calórico total da dieta, conforme adotado em diversos países ${ }^{16}$. Calcula-se que, para a elevação de $1 \%$ no consumo desses ácidos em relação às calorias totais, haja aumento de 0,9\% nos níveis plasmáticos de LDL-c e redução de $1,13 \%$ nas lipoproteínas de alta densidade $(\mathrm{HDL}-\mathrm{C})^{18}$. 0 cream cracker, muito utilizado em recomendações dietéticas, foi considerado uma das principais fontes de ácidos graxos trans consumidos por mulheres e homens americanos ${ }^{19}$.

\section{O N C L U S Ã O}

Considerando os resultad os obtidos neste estudo, deve-se dar maior atenção à ingestão de ácidos graxos trans, pois eles estão presentes em biscoitos, batatas fritas e sorvetes, alimentos que estão entre os mais habitualmente consumidos por adolescentes do Rio de Janeiro ${ }^{10}$.
O relato da composição de alguns produtos não coincidia com os teores encontrados nas análises, destacando-se em muitas amostras teores elevados de ácidos graxos trans, especialmente 0 ácido elaídico. Como os tipos de alimentos analisad os são freqüentes no hábito alimentar da população do Rio de Janeiro, acredita-se que haja necessidade de esses consumidores conhecerem os reais teores de ácidos graxos trans nos alimentos industrializados. Além disso, os produtos com gordura hidrogenada devem sofrer regulamentação mais cautelosa quanto aos teores de ácidos graxos trans ou, ainda, devem ter esses teores claramente identificados em seus rótulos.

\section{REFERÊ N CIAS}

1. World Health Organization. Nutrition. Science Policy. WHO and FAO Joint Consultation: fats and oils in human nutrition. Nutr Rev 1995; 53(7): 202-5.

2. Dietschy JM. Theoretical considerations of what regulates low-density-lipoprotein and high-density-lipoprotein cholesterol. Am J Clin Nutr 1997; 65 (5 Suppl):1581S-9S.

3. Aro A, Jauhiainen $M$, Partanen $R$, Salminen $I$, M utanen M. Stearic acid, trans fatty acids, and dairy fat: effects on serum and lipoprotein lipids, apolipoproteins, lipoprotein(a), and lipid transfer proteins in healthy subjects. Am J Clin Nutr 1997; 65(5):1419-26.

4. Okonek DV, Berben PH, Martelli G. Precious metal catalysis for fats and oils applications. In: Anais do Seminário da Sociedade Brasileira de Óleos e Gorduras, 1996. Gorduras modificadas com baixos teores de ácidos graxos trans: aspectos nutricionais e tecnológicos. São Paulo: Instituto Adolfo Lutz; 1996. p.39-46.

5. M ondini L, M onteiro CA. M udanças no padrão de alimentação. In: M onteiro CA, organizador. Velhos e novos males da saúde no Brasil: a evolução do país e de suas doenças. São Paulo: Hucitec; 1995. p.79-92. 
6. Valenzuela A, King J, Nieto S. Trans fatty acid from hydrogenated fats: The controversy about health implications. Grasas y Aceites 1995; 46(6): 369-75.

7. Soares $L M V$, Franco M RB. Níveis de trans isômeros e composição de ácidos graxos de margarinas nacionais e produtos hidrogenados semelhantes. Ciênc Tecnol Alim 1990; 10(1):57-71.

8. Brasil. Portaria n. 521, de 17/10/97. Ministério da Saúde. Secretaria de Vigilância Sanitária. Food Base. Edição atualizada e revisada até setembro de 1997. (Informação Nutricional Complementar, 521-97).

9. Food and Drug Administration. FDA proposes new rules for trans fatty acids in nutrition labeling, nutrient content clains, and health clains. [cited 1999 Out 29]. Available from: www.access.gpo. gov/su_docs.

10. Chiara VL, Sichieri R. Consumo alimentar em adolescentes: questionário simplificado para avaliação de risco cardiovascular. Arq Bras Cardiol 2001, 77(4):337-41.

11. Association of Official Analytical Chemists. Official methods of analysis. Arlington; 1990. p.91.

12. Geuking W. Factors Determining Trans Isomerization in Partial Hydrogenation of Edible Oils. In: Anais do 6th. Congreso y Exposición Latinoamericanos sobre Processamiento de Grasas y Acetes. Campinas; 1995. p.139-42.

13. International Life Sciences Institute. Trans fatty acids and coronary heart disease risk. Report of the expert. Panel on trans fatty acids and coronary heart disease. Am J Clin Nutr 1995; 62(3 Suppl): 518-26.

14. Santana DMN, Marques MM, Rosa CAR. Determinação por cromatografia gasosa da composição em ácidos graxos e teor de ácido graxo trans oléico em algumas marcas de batatas fritas. Bol Soc Bras Ciênc Tecnol Alim 1999; 33(1):64-9.

15. Kawashima LM , Soares LM V. Gordura em Sorvetes Nacionais: conteúdo, composição de ácidos graxos e teor de trans-isômeros. Ciênc Tecnol Alim 1993; 13(2):194-202.

16. Bolton SC, Woodward M, Fenton S, M cclusey MK, Brown CA. Trans fatty acids in the Scottish diet - an assessment using a semi-quantitative food-frequency questionnaire. Br J Nutr 1995; 74(63):661-70.

17. Jones PJH, Kubow S. Lipids, Sterols, and Their Metabolites. In: Shils ME. Modern nutrition in health and disease. Part A. Major Dietary Constituents and Energy Needs. 9th. Philadelphia: Lippincott Williams \& Wilkins; 2000. p.67-93.

18. Bender DA, Bender AE. Nutrition: a reference handbook. New York: Oxford University Press; 1997.

19. Lemaitre RN, King IB, Patterson RE, Psaty BM , Kestin M, Heckbert SR. Assessment of trans-Fatty Acid Intake with a Food Frequency Questionnaire and Validation with Adipose Tissue Levels of trans-Fatty Acids. Am J Epidemiol 1998; 148(11):1085-98.

Recebido para publicação em 3 de julho de 2001 e aceito em 7 de maio de 2002. 